\title{
Estenosis subaórtica en paciente jóven con antecedente de cirugía cardíaca
}

\author{
Luis María Benitez Sienra \\ Alberto Concepción Marecos Baruja
}

Servicio de Cardiología no invasiva. Hospital Central-Instituto de Previsión Social. Asunción. Paraguay

\section{Correspondencia}

Luis María Benitez Sienra

luismabenitezs@hotmail.com

Recibido: 07/04/2020

Aceptado:28/02/2021

En línea: 30/04/2021

Citar como: Benitez-Sienra L, Concepcion Marecos-Baruja A. Estenosis subaórtica en paciente joven con antecedente de cirugía cardiaca. Rev Ecocar Pract (RETIC). 2021 (Abril); 4 (1): 15-17. doi: 10.37615/retic.v4n1a7.

Cite this as: Benitez-Sienra L, Concepcion Marecos-Baruja A. Subaortic stenosis in a young patient with previous cardiac surgery. Rev Ecocar Pract (RETIC). 2021 (Abril); 4 (1): 15-17. doi: 10.37615/retic.v4n1a7.

\section{Palabras clave}

$\triangleright$ Estenosis subaórtica

$\triangleright$ Tejido mitral accesorio

$\triangleright$ Ecocardiografía transesofágica

\section{Keywords \\ $\triangleright$ Subaortic stenosis \\ $\triangleright$ Accessory mitral tissue \\ $\triangleright$ Transesophageal \\ echocardiography}

\section{Presentación del caso}

Se trata de un paciente masculino de 18 años que acude a nuestro hospital por cuadro de disnea progresiva que empeora con el ejercicio. Como antecedente patológico personal de valor refiere cirugía cardiaca por soplo hace 2 años en otra institución (no precisa diagnóstico preoperatorio ni cuenta con estudios de última internación). Menciona además que los hallazgos operatorios fueron inconclusos, niega que se le haya practicado implante de prótesis o cualquier tipo de reparación quirúrgica. Abandona seguimiento posterior a dicho evento.

En la exploración física se constató impulso apical sistólico incrementado y soplo expulsivo en foco aórtico III/IV, áspero, con irradiación a vasos del cuello y fenómeno de Gallavardin, por lo que se decidió su internación para diagnóstico y estudio de cardiopatía congénita de etiología valvular probable.

El electrocardiograma de superficie se encontraba en ritmo sinusal, con datos de hipertrofia ventricular izquierda y sobrecarga sistólica del ventrículo izquierdo. La radiografía de tórax sugería crecimiento ventricular izquierdo por aumento del índice cardiotorácico.
Se realizó un ecocardiograma transtorácico donde se evidenció hipertrofia concéntrica del ventrículo izquierdo, función sistólica del ventrículo izquierdo conservada con fracción de eyección del 72\% por método Teichholz. A nivel del tracto de salida del ventrículo izquierdo (TSVI) se constató obstrucción subaórtica importante con gradiente máximo de $82 \mathrm{mmHg}$, asociado a una estructura de tejido unida a la valva anterior mitral y que protruía en sístole. No se observan otras alteraciones estructurales significativas. La válvula aórtica era tricúspide con buena apertura y movilidad, con regurgitación leve; válvula mitral levemente engrosada, con buena apertura de sus valvas y regurgitación leve (Figura 1-3, Videos 1 y 2 ).

Como diagnósticos diferenciales se plantearon:

1. Membrana subaórtica.

2. Tejido mitral accesorio.

3. Cuerda supernumeraria.

Se solicitó ecocardiograma transesofágico (ETE) como examen complementario y se observaron una estructura que obstruía el TSVI insertada en la cara ventricular de la mitral y con cuerdas al tabique interventricular sugerente de tejido mitral accesorio. (Videos 3- 5). Se identifica con mucha claridad la insuficiencia aórtica y mitral asociada ambas excéntricas 


\section{Estudio por imagen}



Figura 1. Ecocardiografía transtorácica (ETT) en modo M, plano eje largo paraesternal, muestra el aumento del grosor parietal izquierdo



Figura 2. ETT bidimensional (2D), plano eje apical 5 cámaras, evidencia el flujo espectral turbulento por Doppler continuo en el tracto de salida del ventrículo izquierdo (TSVI). Presenta un gradiente máximo de $82 \mathrm{mmHg}$ y una leve regurgitación aórtica, nótese el leve retraso en el tiempo de ascenso del flujo sistólico al pico de velocidad máxima

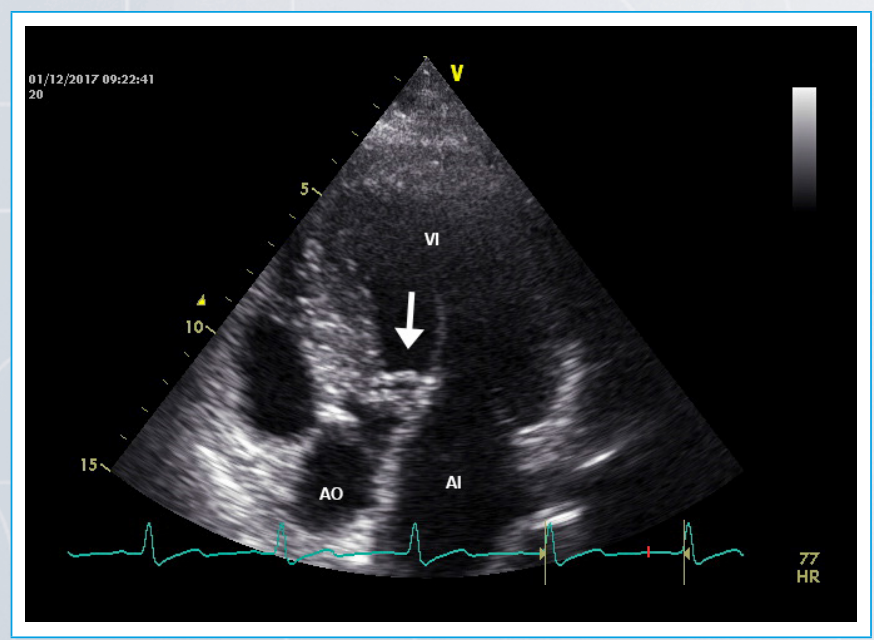

Figura 3. ETT 2D plano eje apical 5 cámaras, se visualiza una estructura a pocos milímetros por debajo del plano valvular aórtico que se adhiere al septum interventricular y a la valva anterior mitral

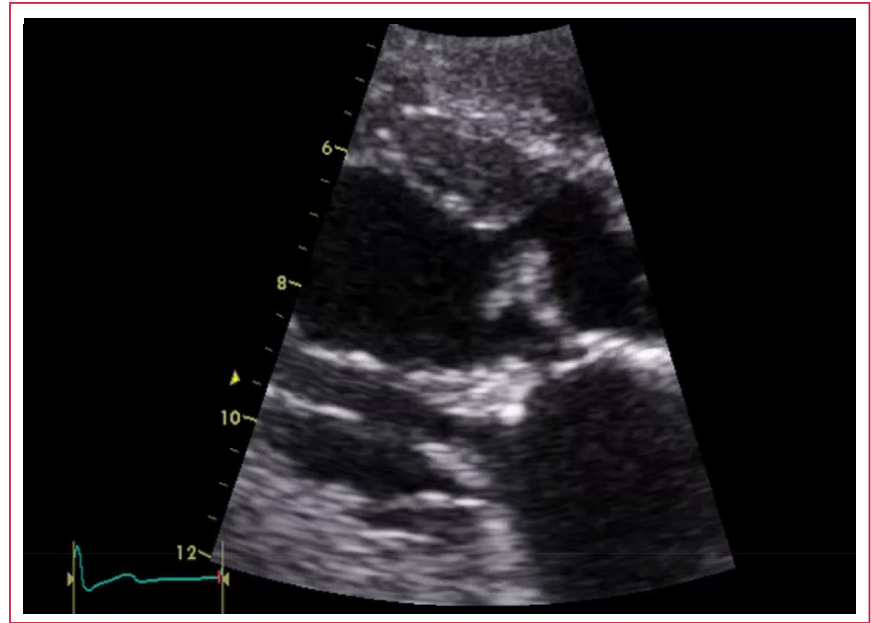

Vídeo 1. ETT 2D, plano eje largo paraesternal, se observa la misma estructura ocupando gran parte del TSVI. Nótese como presenta protrusión en sístole cardiaca.

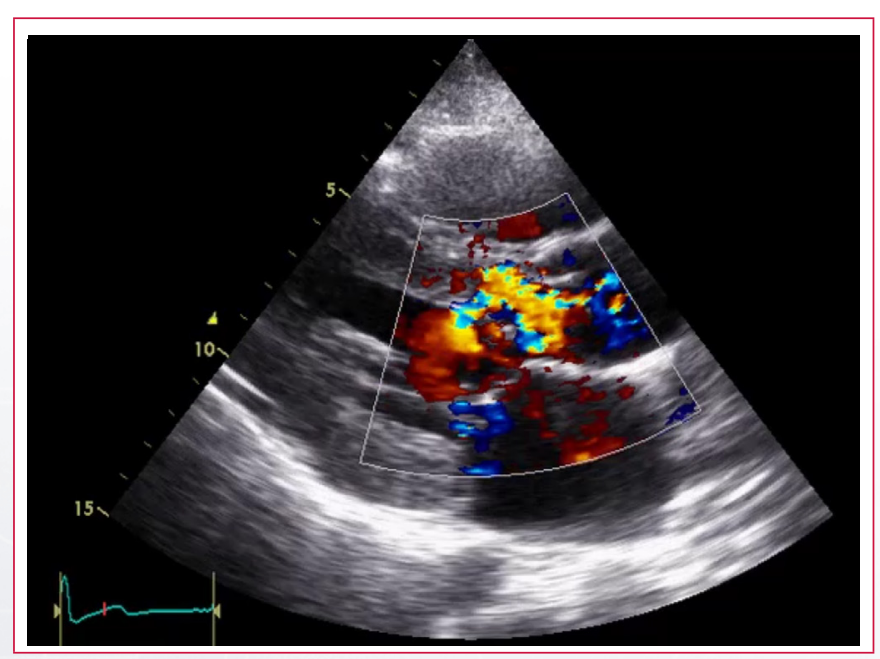

Vídeo 2. ETT 2D, plano eje largo paraesternal, con Doppler color donde se puede evidenciar el aliasing prevalvular aórtico en el TSVI. Se observa además un jet de regurgitación mitral excéntrico posterior delgado

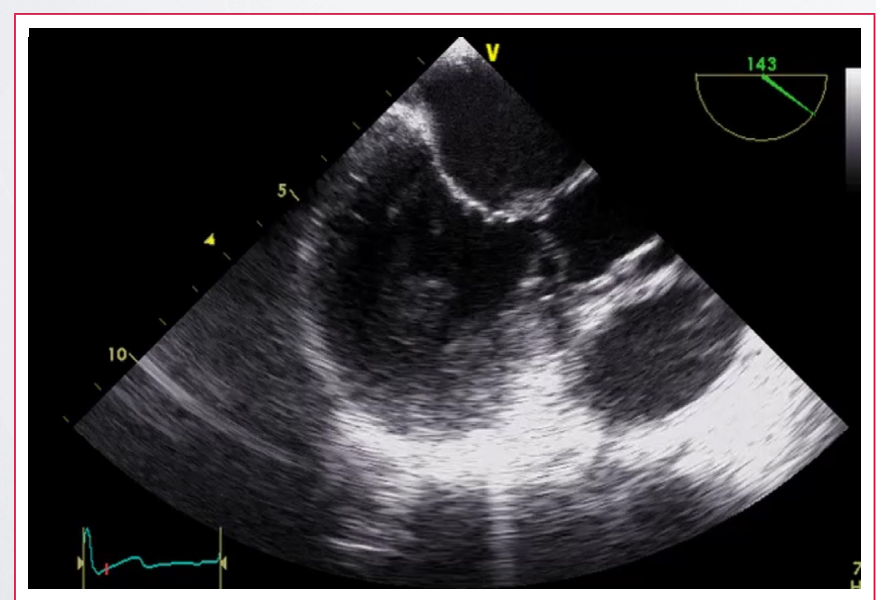

Vídeo 3. Ecocardiografía transesofágica (ETE) 2D, plano eje largo del ventrículo izquierdo (VI), se observa la implantación del tejido accesorio en la valva anterior mitral con protrusión del mismo en sístole y su desaparición en diástole, así como su anclaje mediante cuerdas al tabique interventricular. Además, se observa pequeña deformidad en la hoja anterior de la mitral en el sitio opuesto a la membrana 




Vídeo 4. ETE 2D, plano eje largo del VI, con Doppler color se observa el aliasing en el TSVI. Además de un jet de regurgitación aórtica excéntrico y nuevamente la regurgitación mitral excéntrica posterior con deformidad de la hoja anterior mitral especialmente visto en diástole

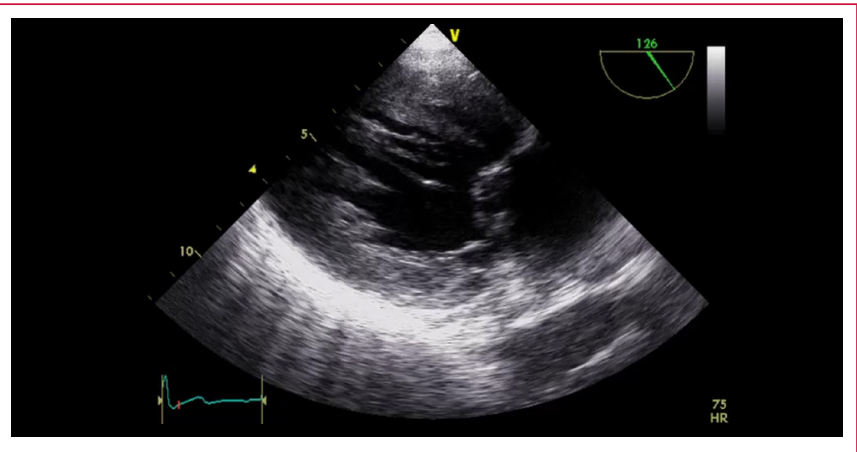

Vídeo 5. ETE 2D, plano eje transgástrico, muestra varias cuerdas insertadas al tabique interventricular y a la cara ventricular de la valva anterior mitral. Nuevamente se observa algo de anormalidad de parte de la hoja anterior de la mitral, tipo prolapso

\section{Discusión}

La estenosis subaórtica, es la obstrucción deI TSVI por debajo de la válvula aórtica causada por un exceso de tejido o por anomalías congénitas propias de cualquiera de las estructuras que conforman el TSV|(1).

Una característica importante de la estenosis subaórtica es la diversidad de lesiones cardíacas con las que se relaciona y la inconsistencia de los términos usados para su clasificación, debido a que se utiliza la misma terminología para definir condiciones patológicas distintas y a su vez, se emplea una variedad de nombres para designar lesiones idénticas ${ }^{(1)}$.

La obstrucción del TSVI por tejido mitral accesorio es muy rara, habiendo otras causas más frecuentes de estenosis subaórtica, a saber: membrana discreta, rodete fibroso subaórtico, miocardiopatía septal asimétrica obstructiva, mala disposición de las cuerdas tendinosas y de los músculos papilares y la desviación posterior del septum infundibular. Mac Lean et al, describen el primer caso de esta anomalía en 1963 en un paciente de 29 años. En el 63\% de los casos, esta patología se encuentra asociada a otro tipo de defecto cardíaco congénito, siendo el más común la comunicación interventricular. Clínicamente, los pacientes pueden estar asintomáticos, aunque también se han descrito síntomas de insuficiencia cardíaca, síncope y dolor precordial(2)

En nuestro caso el paciente presentó disminución de la clase funcional de manera progresiva con una historia clínica previa de cirugía cardiaca por so- plo cardiaco. Mediante la realización de ecocardiograma bidimensional (2D) - Doppler, se evidenció una estructura que generaba una obstrucción importante en el TSVI. Entre los diagnósticos diferenciales se planteó la presencia de una membrana subaórtica, tejido mitral accesorio y cuerda supernumeraria. La literatura sugiere otros diagnósticos a ser tomados en cuenta de acuerdo al contexto clínico del paciente como masas ventriculares tales como tumores (mixomas, fibroelastomas) o vegetaciones, ya que pueden producir imágenes ecocardiográficas similares ${ }^{(3)}$

El diagnóstico de tejido mitral accesorio se confirmó mediante ETE, al detectarse una estructura de tejido unida a la cara ventricular de la valva anterior mitral y que protruía en sístole en el TSVI. La ETE aporta información adicional al definir con claridad la naturaleza, morfología, en nuestro caso, los puntos de inserción del tejido mitral accesorio y también para concretar la conducta a seguir con el paciente. Esta aseveración es comprobada en el acto quirúrgico (la utilización intraoperatoria/posoperatoria del ETE permite comprobar "in situ" la desaparición de la obstrucción al TSVI, así como el funcionamiento de la válvula mitral)(1). Lo que nos lleva a concluir que no se ha realizado monitorización con ETE en la cirugía cardiaca previa de nuestro paciente para precisar el diagnóstico correcto.

La Ecocardiografía tridimensional (3D) permite una visualización más precisa de la válvula mitral desde ambas perspectivas (vista ventricular izquierda y auricular izquierda) $)^{(4)}$. Los resultados quirúrgicos en la actualidad son buenos y los pacientes permanecen asintomáticos, sin que se haya descrito obstrucción subaórtica recurrente ${ }^{(1)}$.

\section{Conclusión}

Es de suma relevancia obtener una información clínica adecuada de cada paciente y de un trabajo en conjunto (cardiólogo clínico, ecocardiografista y el cirujano), a fin de poder clasificar estas entidades, tomando en cuenta la importancia que esto tiene desde el punto de vista pronóstico y en la toma de decisiones para su resolución.

El ecocardiograma transesofágico como examen complementario es una herramienta de gran utilidad para el diagnóstico de tejido mitral accesorio.

\section{Ideas para recordar}

- Cuando existe obstrucción subaórtica, suele deberse a la presencia de una membrana fibromuscular; o bien, a inserciones anómalas de la valva anterior izquierda, que provocan una estrechez en el TSVI, siendo excepcional, como en este caso, que sea por tejido mitral accesorio.

- El ecocardiograma transesofágico es una herramienta de gran valor, no sólo para realizar el diagnóstico, sino también para definir la conducta a seguir con el paciente.

\section{Bibliografía}

1. Hamana L, Blandenier de Suárez C. Caracterización histopatológica de la estenosis subvalvular aórtica: Estudio de 24 biopsias. RFM. Caracas. 2006; 29. (1).

2. Aguilar Iñigo C, et al. Estenosis subaórtica progresiva causada por tejido mitral accesorio. Rev Esp Cardiol. 1999; 52: 438-440.

3. González l., et al. Obstrucción del tracto de salida del ventrículo izquierdo por tejido mitral accesorio. Revisión del tema a propósito de un caso. Rev. Cubana Cardiol. Cir. Cardiovasc. 2011; 17 (3): 284-89.

4. Rabischoffsky A, et al. Accessory Mitral Valve Tissue: An Unusual Echocardiographic Finding. CASE: Cardiovascular Imaging Case Reports. 2018; 2, (1). 